\title{
Reliability of the Panoramic Imaging Compared to Cone-beam Computed Tomography in Determining the Relationship of the Third Molar to the Mandibular Canal
}

\author{
${ }^{1}$ Farah AM Azahar, ${ }^{1}$ Aung L Oo, 1,2 Phrabhakaran Nambiar, ${ }^{3}$ Sathick Manzoor, ${ }^{2}$ Nisreen M AL-Namnam
}

\begin{abstract}
Background: The incidence of injury to the inferior alveolar nerve during mandibular molar extraction increased the demand for pre-surgical planning to avoid any complications.

Aim: To investigate the diagnostic accuracy of the dental panoramic image compared to cone-beam computed tomography (CBCT) in predicting the inferior alveolar nerve (IAN) exposure during impacted third molar extraction.
\end{abstract}

Materials and methods: This is a prospective study of consecutive patients, consulted for third molar extraction under local anesthesia. Thirty-two patients showed sign of proximity of the roots of the third molars to the mandibular canal from the dental panoramic image, were selected for CBCT.

Results: With respect to the interobserver reliability, no significant difference $(p<0.05)$ was observed for the prediction on nerve exposure and injury from the dental panoramic image, however, showed a significant difference $(p=0.001)$ for the cone-beam computed tomography. The prevalence of contact between the third molar to the inferior alveolar canal (IAC) was $96.8 \%$ with a significant finding $p=0.002$. There was a significant difference in the loss of cortex in predicting nerve exposure with $p=0.04$. Clinically, three patients had nerve exposure and two patients had neurosensory disturbances.

Conclusion: Dental panoramic image is still valuable for predicting the proximity of the third molar to the inferior alveolar canal. Nevertheless, CBCT has the best precision in localizing the close contact between the third molar and the inferior alveolar canal.

Clinical significance: There was no significant finding from the CBCT for the incidence of the inferior alveolar nerve exposure and injury. However, it was seen to be accurate in predicting the IAN exposure. All these findings prove that cone-beam computed tomography contributes in the surgical plan, reduced operative time and patient morbidity.

\footnotetext{
${ }^{1}$ Department of Oral and Maxillofacial Clinical Sciences, University of Malaya, Kuala Lumpur, Malaysia

${ }^{2}$ Department of Oral Biology, MAHSA University, Bandar Saujana Putra, Malaysia

${ }^{3}$ Department of Oral Radiology, MAHSA University, Bandar Saujana Putra, Malaysia

Corresponding Author: Nisreen M AL-Namnam, Department of Oral Biology, MAHSA University, Bandar Saujana Putra, Malaysia, e-mail: nisreenmohammed@mahsa.edu.my
}

Keywords: Cone-beam computed tomography, Dental panoramic tomography, Inferior alveolar canal mandibular, Third molar tooth.

How to cite this article: Azahar FAM, Oo AL, Nambiar $P$, Manzoor S, AL-Namnam NM. Reliability of the Panoramic Imaging Compared to Cone-beam Computed Tomography in Determining the Relationship of the Third Molar to the Mandibular Canal. World J Dent 2018;9(6):481-488.

Source of support: This research was fully funded by the University of Malaya Research grant (PPPC/C1-2012/DCGB/31).

Conflict of interest: None

\section{INTRODUCTION}

The surgical removal of the mandibular third molar tooth is one of the most common procedures in oral and maxillofacial surgery. This procedure has the possibility of unintentional impairment to the inferior alveolar nerve (IAN) which is contained in the inferior alveolar canal (IAC). From this surgery, neurological complications may occur as a result of improperly applied surgical methods or insufficient assessments of the surrounding anatomical structures.

Studies have shown that neurological complications vary from $0.5-1 \%$ for permanent damage and $1-5 \%$ involving temporary damage. ${ }^{1}$ The occurrence of damage to inferior alveolar nerve increases to $30 \%$ when a close relationship between the third molar and the mandibular canal exist radiographically. ${ }^{2}$ Therefore, it is important to assess the position and establish the relationship of the impacted third molar with the IAC preoperatively to minimize the risk of nerve injury.

A dental panoramic image (DPI) is routinely employed to evaluate the relationship between the third molar to the IAC prior to surgery. Many specific signs on DPI have been used as indicators for close proximity of the IAC to the tooth. Darkening of the root, deflection of the root, narrowing of the roots, bifid root apex, diversion of the canal, narrowing of the canal and interruption of the white line of the canal are standard radiological markers using till now or the initial evaluation of the likelihood of risk of damage to the IAN. ${ }^{3}$ Nevertheless, there is a lack of accuracy in these radiological markers to be used as a guide.

To overcome misinterpretations of the exact position of the canal, a CBCT is employed to evaluate the position 
of the mandibular molar teeth and the anatomic relation with the IAC. It provides three-dimensional views, clear visualization of the canal and better quality images of teeth and their surrounding structures. ${ }^{4}$

Even though there were many studies regarding IAN injury in surgical removal of the third molar, it is still necessary to elaborate the benefit of CBCT versus DPI because of the inconsistent findings. Therefore, the aim of this study was to assess the diagnostic accuracy of DPI When compared to CBCT in predicting IAN exposure and injury during mandibular third molar extraction.

\section{MATERIALS AND METHODS}

\section{Ethics Statement}

This study received approval from the Medical Ethics Committee, Faculty of Dentistry, University of Malaya [DF OS1213/0080(P)].

\section{Study Sample/Design}

This is a prospective interventional study of consecutive patients who referred for mandibular third molar extraction under local anesthesia. Sixty patients have been selected for the study at Department of Oro-Maxillofacial Surgical and Medical Sciences, Faculty of Dentistry, University of Malaya. Patients $(n=32)$ who are eligible for this study were those who are indicated for removal and showed an intimate relationship of mandibular third molar to the inferior alveolar canal based on the preoperative DPI. CBCT scanning for further radiological assessment before undergoing the surgery has been indicated. Exclusion criteria were; a pregnant woman, patients whose third molars are associated with periapical inflammatory, cystic lesions, infection, and any systemic condition.

\section{Panoramic Imaging System}

Dental panoramic imaging was taken using Orthopos XG5 (German); Morita Veraviewepocs (Japan); and Instrumentarium (Finland) extraoral imaging system. The exposure from panoramic radiograph is $68 \mathrm{kV} 8 \mathrm{~mA}$ (14.1s); $70 \mathrm{kV} 8$ $\mathrm{mA}(14.9 \mathrm{~s})$ and $66.27 \mathrm{kV} 67 \mathrm{~mA}$ (17.6s), respectively.

\section{Cone-beam Computed Tomography Imaging System}

The CBCT images were taken using the I-CAT conebeam computed tomography machine, manufactured by Imaging Sciences International Inc., Hatfield USA. The images were taken following a standardized protocol for exposure parameter setting (120 kVp, 3e7 mA, 20s), patient positioning, and image acquisition at $0.3 \mathrm{~mm}$ voxel size.

\section{Imaging Assessment}

Evaluation of images was carried out by one maxillofacial radiologist and one maxillofacial surgeon, familiar with both the imaging modalities and experienced in diagnosing maxillofacial structures. They evaluated the images independently and were not involved with the surgery. They were looking for the relationship between the impacted mandibular third molar and the IAC canal according to the criteria listed below. The observers assessed the first DPI and then CBCT images at a week intervals.

Panoramic image was evaluated for the presence or absence of four important radiological features; interruption of the white line (loss of cortex), darkening of the root (radiolucent band), diversion (change in the canal direction) and narrowing of the mandibular canal. Whereas with the CBCT, the relationship of the third molar to the IAC was determined by looking into the contact of the root to the IAC and its buccolingual position to this canal. Interobserver agreement was evaluated using Kappa statistics to determine the consistency amongst the observers.

\section{Surgical Procedure}

The surgical removal of the impacted mandibular third molar was carried out by a selected group of maxillofacial surgeons. A standard technique was approved and agreed before the study started which was consisting of a buccal mucoperiosteal flap (stander ward's incision) and guttering the surrounding bone of the crown. Subsequently, sectioning of the crown (when necessary), elevation of the tooth, debridement and suturing with resorbable sutures was undertaken. Thirty-five teeth were extracted from 32 patients. Only DPI of the patients was provided during the surgery. Every patient scheduled for surgery was informed of possible complications. Verbal and written consent was taken from the patients before the surgery. A performa was used to document the intraoperative findings and the postoperative sequelae.

\section{Assessment of Clinical Neurosensory Test (CNT) Post-surgery}

The patency of the nerve for the presence or absence of a neurosensory deficit in all patients were reviewed and assessed preoperatively and reviewed 1 week, one month, two months and sixth month postoperatively by the first author. The clinical neurosensory test (CNT) was performed by subjective and objective assessment. The presence or absence of a trigger was recorded for each patient.

The subjective assessment was done by visual analog for indicating their lines of perception on the current level of sensation. Objective assessment of CNT involved three levels: A, B, and C. It involved a drop out an algorithm 
that attempts to correlate the result of the test with the level of nerve injury. ${ }^{5,6}$ The IAN testing was performed over a $1 \mathrm{~cm}$ area on the labiomental fold of the injured and uninjured sides of the chin.

\section{RESULTS}

The study sample consisted of 35 impacted mandibular third molars from 32 patients ( 9 males and 23 female). Statistically, no significant agreement (Kappa $=0.273$, $\mathrm{p}=0.059$ ) between two observers (the oral radiologist and the surgeon) in predicting nerve exposure and injury from DPI (Table 1).

It was further observed that the incidence of loss of cortex was found to be higher with observer one in comparison with observer two which accounted for $91.40 \%$ and $85.71 \%$ respectively. The narrowing of the canal was the second-highest found by observer 1 (71.4\%), while darkening of the root was found to be the second most by observer 2 (34.39\%). Although the high incidence of loss of cortex is associated with nerve exposure was found in both observers. Statistically, only one observer showed a significant result (observer 1). With statistical significance $(p=0.03 ; p>0.05)$ using Chi-square test, $82.86 \%$ was expected by this observer to have nerve exposure among 32 cases that have loss of cortex. From observer

Table 1: Kappa statistical analysis of interobserver prediction on nerve exposure from DPT

\begin{tabular}{lllll}
\hline & \multicolumn{3}{c}{$\begin{array}{c}\text { Prediction of nerve } \\
\text { exposure observer } 2\end{array}$} \\
\cline { 2 - 4 } & No & Yes & Total \\
\hline & No & 2 & 3 & 5 \\
Prediction of & & $(5.71 \%)$ & $(8.57 \%)$ & $(14.29 \%)$ \\
\cline { 2 - 5 } $\begin{array}{l}\text { nerve exposure } \\
\text { observer 1 }\end{array}$ & Yes & 5 & 25 & 35 \\
\cline { 2 - 5 } & & $(14.29 \%)$ & $(71.43 \%)$ & $(80.00 \%)$ \\
\cline { 2 - 4 } & Total & 7 & 28 & 35 \\
& & $(20.00 \%)$ & $(80.00 \%)$ & $(100 \%)$ \\
\hline
\end{tabular}

Table 3: Prevalence of contact between mandibular third molar tooth to inferior alveolar canal from CBCT

\begin{tabular}{lllll}
\hline & & \multicolumn{2}{c}{ CBCT contact observer 2} & \\
\cline { 3 - 4 } & & No & Yes & Total \\
\hline \multirow{3}{*}{$\begin{array}{lllll}\text { CBCT } \\
\text { contact }\end{array}$} & No & 3 & 3 & 5 \\
observer 1 & & $(8.57 \%)$ & 1 & $(28.57 \%)$ \\
\cline { 2 - 5 } & & 1 & 4 & 25 \\
& Total & $(2.86 \%)$ & 30 & $(71.43 \%)$ \\
& & $(11.43 \%)$ & 31 & 35 \\
& & & 31 & $100 \%)$ \\
\hline
\end{tabular}

$2,34.29 \%$ was expected to have nerve exposure among 12 cases with darkening of the root with a significance value of $p=.07(p<0.05)$.

A moderate agreement between the two observers has been found with a significant value of $p=0.001$, using interobserver reliability test, in predicting nerve disturbances from CBCT (Table 2).

Prevalence of contact between mandibular third molar and IAC from CBCT had a substantial agreement between the two observers with Kappa value $=0.718$ and significant findings of $p<0.0001$ (Table 3).

The inter-observer reliability in predicting the buccolingual position of the canal from the mandibular third molar was found to be significant on the inferior $(p=0.04)$ and lingual $(p=0.01)$ position (Table 4$)$.

The surgery time taken for each case ranges from 10 to 63 minutes to complete. Two patients sustained paraesthesia postoperatively while in three cases, nerve exposure was evident (Table 5).

Table 2: Kappa statistical analysis of interobserver prediction on nerve disturbance from $\mathrm{CBCT}$

\begin{tabular}{lllll}
\hline & & \multicolumn{3}{c}{$\begin{array}{c}\text { Prediction of Nerve } \\
\text { exposure observer } 2\end{array}$} \\
\cline { 2 - 4 } & No & Yes & Total \\
\hline & 5 & 3 & 5 \\
Prediction & & $(14.29 \%)$ & $14.29 \%)$ & $(28.57 \%)$ \\
\cline { 2 - 4 } $\begin{array}{l}\text { of Nerve } \\
\text { Disturbance }\end{array}$ & Yes & 1 & 24 & 25 \\
Observer 1 & Total & 6 & $(68.57 \%)$ & $(71.43 \%)$ \\
\cline { 2 - 4 } & & $(17.14 \%)$ & 29 & 35 \\
& & & $(82.86 \%)$ & $100 \%)$ \\
\hline
\end{tabular}

Table 4: Kappa statistical analysis of interobserver on inferior and lingual positions of ICA to mandibular third molar

\begin{tabular}{|c|c|c|c|c|}
\hline & & \multicolumn{2}{|c|}{ Inferior position observer 2} & \multirow[b]{2}{*}{ Total } \\
\hline & & No & Yes & \\
\hline \multirow{6}{*}{$\begin{array}{l}\text { Prediction } \\
\text { of nerve } \\
\text { exposure } \\
\text { observer } 1\end{array}$} & No & 8 & 6 & 14 \\
\hline & & $(22.86 \%)$ & $(17.14 \%)$ & $(40.00 \%)$ \\
\hline & Yes & $\begin{array}{l}5 \\
(14.26 \%)\end{array}$ & $\begin{array}{l}16 \\
(45.71 \%)\end{array}$ & $\begin{array}{l}21 \\
(60.00 \%)\end{array}$ \\
\hline & Total & $\begin{array}{l}13 \\
(37.14 \%)\end{array}$ & $\begin{array}{l}22 \\
(62.86 \%)\end{array}$ & $\begin{array}{l}35 \\
(100 \%)\end{array}$ \\
\hline & & \multicolumn{2}{|c|}{ Lingual position observer 2} & \\
\hline & & No & Yes & Total \\
\hline \multirow{3}{*}{$\begin{array}{l}\text { Prediction } \\
\text { of nerve } \\
\text { exposure } \\
\text { observer } 1\end{array}$} & No & $\begin{array}{l}22 \\
(62.86 \%)\end{array}$ & $\begin{array}{l}0 \\
(0.00 \%)\end{array}$ & $\begin{array}{l}22 \\
(62.86 \%)\end{array}$ \\
\hline & Yes & $\begin{array}{l}7 \\
(20.00 \%)\end{array}$ & $\begin{array}{l}6 \\
(17.14 \%)\end{array}$ & $\begin{array}{l}13 \\
(37.14 \%)\end{array}$ \\
\hline & Total & $\begin{array}{l}29 \\
(82.86 \%)\end{array}$ & $\begin{array}{l}6 \\
(17.14 \%)\end{array}$ & $\begin{array}{l}35 \\
(100 \%)\end{array}$ \\
\hline
\end{tabular}

Table 5: Incidence of surgery time taken with postoperative paroesthesia

\begin{tabular}{llll}
\hline Surgery time taken $(\mathrm{min})$ & Paresthesia postop & No Paresthesia postop & Total \\
\hline$<30$ & 2 & 19 & $21(60.0 \%)$ \\
$>30<60$ & 0 & 13 & $13(37.14 \%)$ \\
$>60$ & 0 & 1 & $1(2.86 \%)$ \\
\hline Total & $2(5.7 \%)$ & $33(94.3 \%)$ & $35(100 \%)$ \\
\hline
\end{tabular}


Images of different DPT markers compared to the CBCT findings from selected four cases showed in Figure 1.

\section{DISCUSSION}

\section{Reliability of Four Radiological Markers from DPI}

The interobserver reliability on the prediction of nerve exposure from the DPI in this study was found to be not significant. Likewise, the prediction of the nerve injury from the DPI was also found to be not significant. This is in correspondence with other studies that found that there was no universal agreement on to whether these radiological signs (darkening of the root, deflection of the roots, narrowing of the root, dark and bifid apex of the root, interruption of white lines of the canal, diversion of the inferior alveolar canal, narrowing of the inferior alveolar canal) were the best predictors for nerve exposure or injury. ${ }^{7,8}$

There was no agreement between the two observers regarding the DPI findings. The authors are of the opinion that this different interpretation of the findings could be related to the small sample size and also possible to the image quality of the DPT. Moreover, the radiological markers on the DPI were not precise as compared to the $3 \mathrm{D}$ image recorded by the $\mathrm{CBCT}$ machine.

From 35 cases, two patients sustained paresthesia postoperatively. One case showed signs of darkening of the root and loss of cortex from the DPI. While in the other case there was loss of cortex and narrow canal from the DPT These findings are in agreement to the studies reported by Kipp et al. as they reported that impingement of roots on the canal could be determined radiographically by the appearance of a relative radiolucent area on the root structure (darkening of the root) in the area of the mandibular canal, or even by the appearance of loss of root structure. 9

In this study, three cases had nerve exposure before the removal of the third molar tooth; however, none of them sustained postoperative paraesthesia. From the DPI, these cases showed signs of superimposition and loss of cortex of the canal. Two cases had other associated signs, which were contact and narrowing of the canal, respectively.

The DPI image in Figure 1, Case A shows an interruption of white lines from one of the cases where nerve exposure was noticed. The CBCT image of the same case shows that the roots were inside the IAC, which explained the nerve exposure intraoperatively. The loss of cortex is considered to indicate deep grooving of the root if it appears alone or perforation of the root if it appears with the narrowing of the IAC. Howe and Poyton considered that this sign to be a reliable sign to indicate the accurate proximity of the tooth with the canal. $^{3}$

Sign of darkening of the roots (1 patient) did not have any nerve exposure nor nerve disturbance postoperatively (Fig. 1, Case C). However, one patient who had loss of cortex together with darkening of the root sustained postoperative nerve injury. This may be because the latter had two signs on the DPI that indicated the high risk of nerve exposure and injury. Several studies have supported the above statement, in which presence of two or more signs on the DPT result in an increased risk of IAN exposure and injury. ${ }^{10-12}$ Darkening of the root was due to the close contact between the tooth and canal, which cause density loss of the tooth root.$^{13}$ It was also suggested that this darkening may be related to the thinning of cortex or perforation of the lingual cortical plate. ${ }^{14}$ To sum up, darkening of the root or radiolucent band is one of the indicators of grooving of the tooth by the canal. ${ }^{2,15}$

In the present study, two out of three patients who had nerve exposure showed narrowing of the canal from the DPI. Furthermore, one of the patients who had nerve injury displayed narrowing of the canal as shown in Figure 1, Case D.

The narrowing of the canal implies that the canal has reduced in diameter. ${ }^{16}$ Monaco in 2004 reported that narrowing of the canal was an accurate predictor in $78.6 \%$ of the cases in predicting close relationship of the third molar with IAC. ${ }^{17}$ However, narrowing of the canal was not a commonly observed sign. ${ }^{3}$ In consonance, the result of the present study did not show a significant correlation between narrowing of the canal with nerve exposure and injury.

Based on our radiological evaluation, the diversion of the canal does signify the close relationship of the root to the IAC (Fig. 1, Case B). Moreover, statistically, there was no significant correlation between the diversion of the canal to either nerve exposure or injury. These findings support the results reported by Rood who reported that this sign was not correlated with nerve injury. ${ }^{3}$ On the other hand, Ghaeminia et al. found that the presence of other signs such as the loss of cortex and darkening of the root were significantly associated with IAN exposure. ${ }^{18}$

Although the prediction of having nerve exposure and injury from the DPI was high, the outcomes in this study showed otherwise. Out of 35 cases, only two had sustained nerve injury, which accounts for $5.7 \%$ of the cases. Therefore, the incidence of nerve injury with regard to the close contact of the third molar to the IAC statistically was not significant. Again, caution must be expressed here as the sample size was only 35 cases and this one of the limitations of this study. 


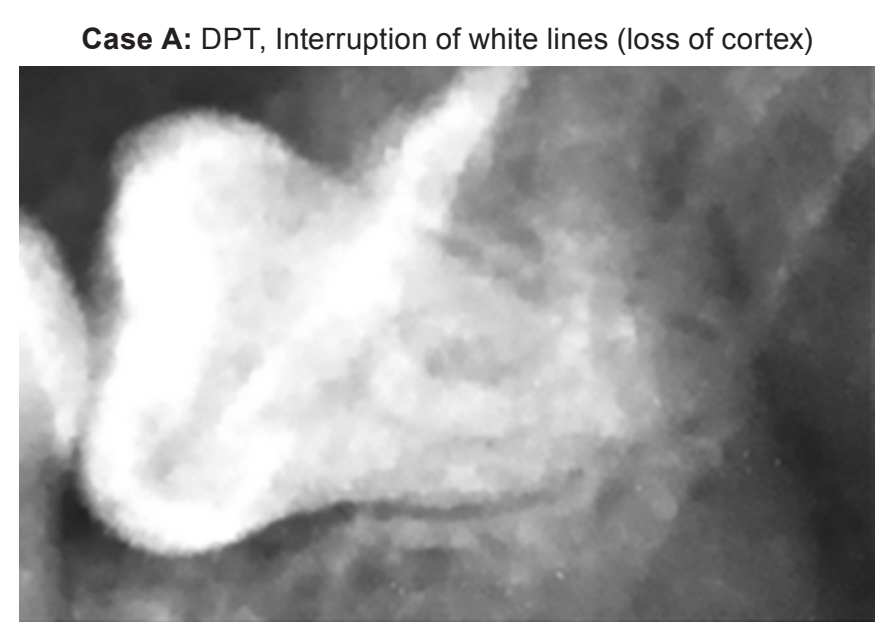

Case B: DPT, diversion of canal (change location)

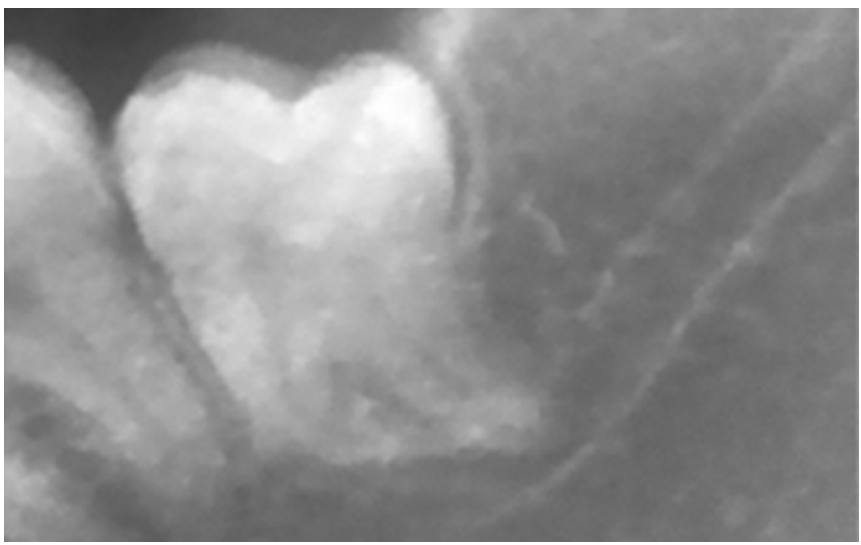

Case C: DPT, darkening the roots (radiolucent band)

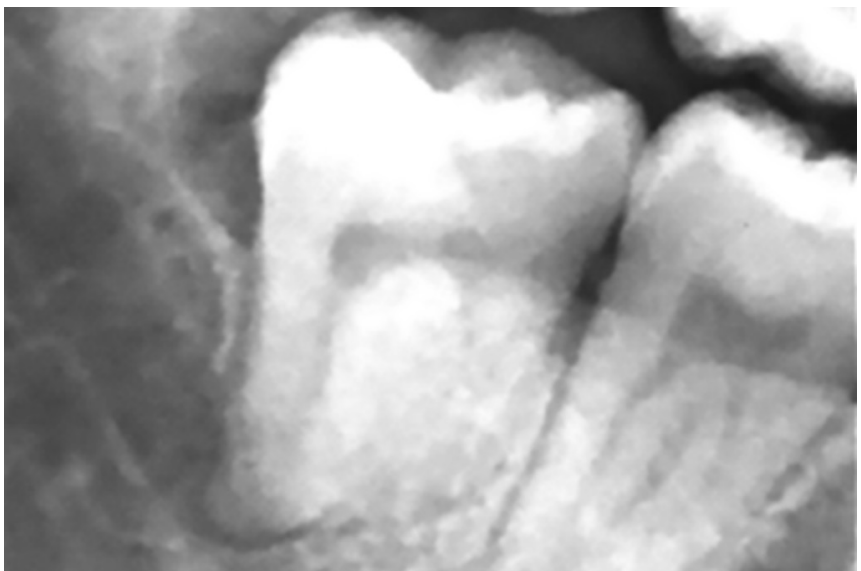

Case D: DPT, narrowing the canal and interruptions of whilte lines

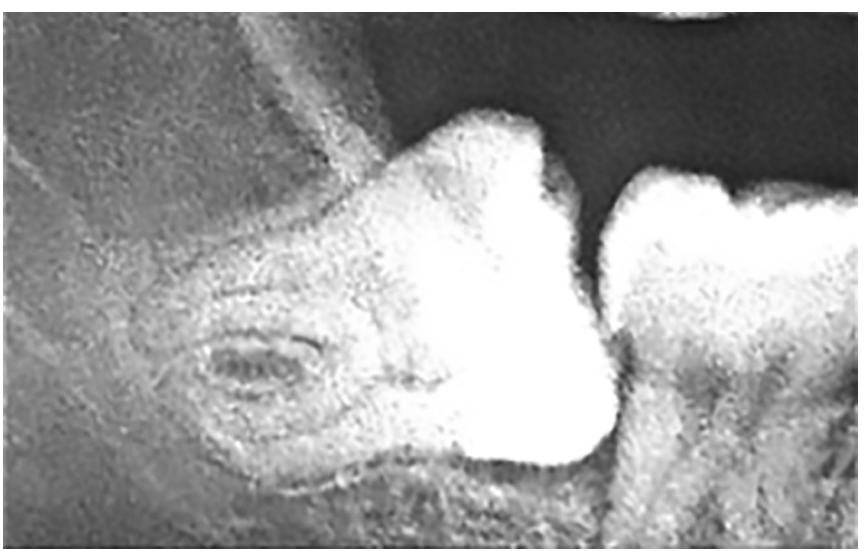

Fig. 1: Images of different DPT markers compared to the CBCT findings from selected four cases

\section{CBCT, 38 roots inside inferior alveolar canal}

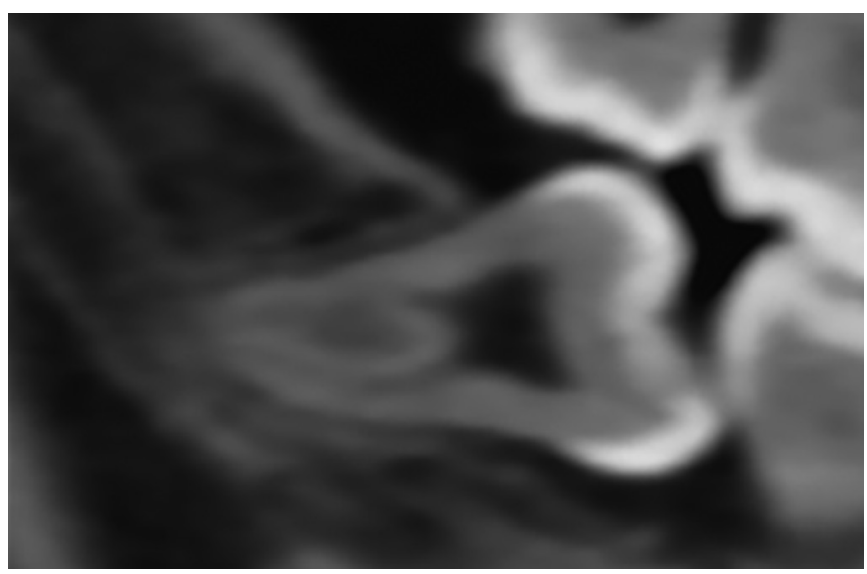

CBCT, 38 roots inside inferior alveolar canal (IAC)

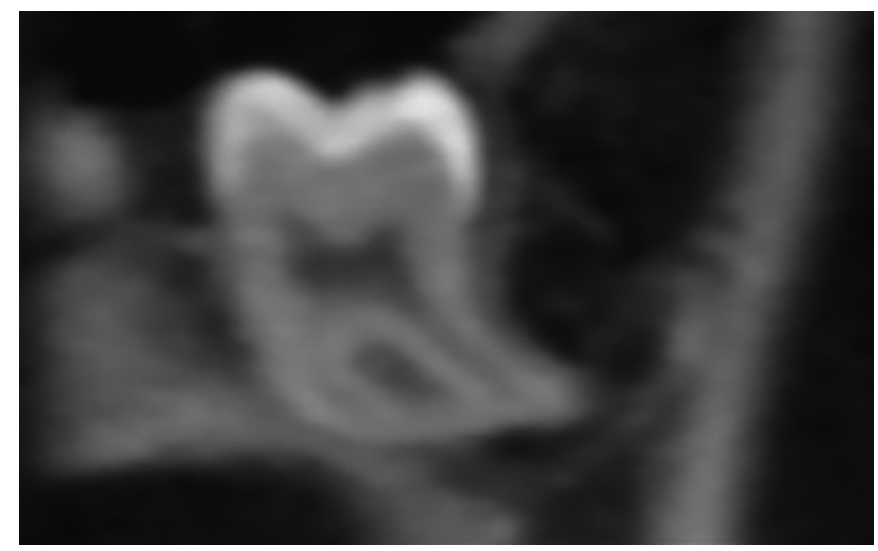

СВCT, inferior alveolar canal is inter-radicular

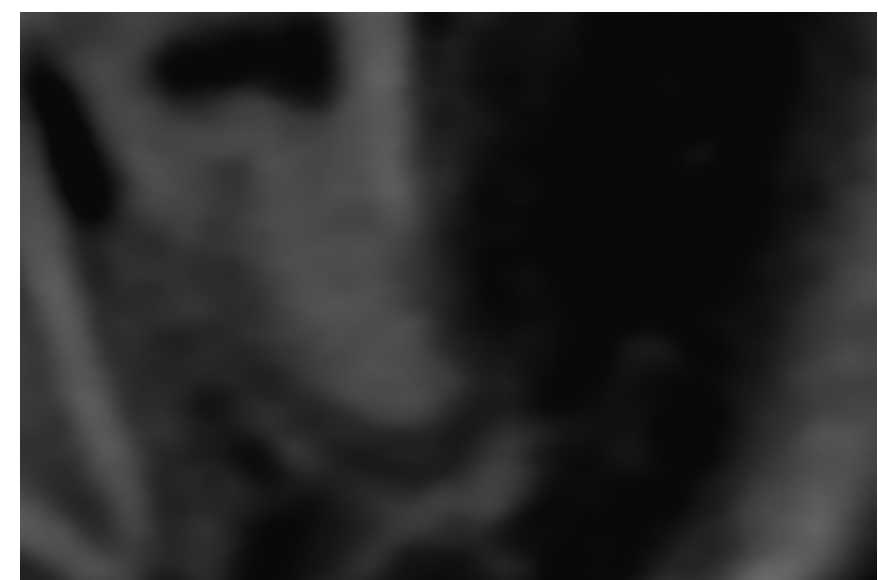

$\mathrm{CBCT}$, inferior alveolar canal is inter-radicular

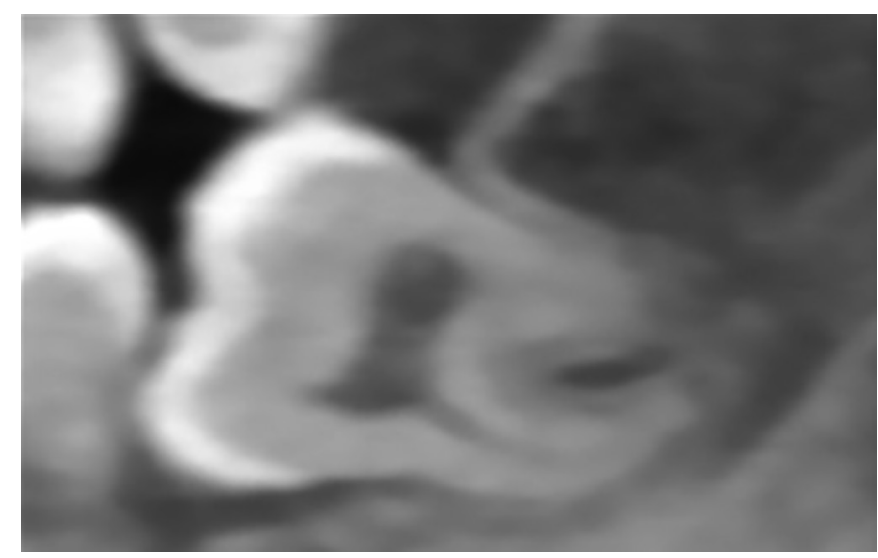


Wenzel justified the failure of the panoramic image to determine the position of the molar teeth (lingual, buccal, or inter-radicular) to the IAC due to its lower sensitivity. ${ }^{19}$ The absence of positive radiographic signs on the DPT is more useful than the presence of such signs. Interestingly, this assessment got a general agreement from most others studies. ${ }^{12,20}$

\section{Reliability of CBCT Image in Determining Close Relationship of Mandibular Third Molar to IAC}

The authors of the present study suggested that the cause of the significantly and moderate agreement of the interobserver reliability results on the prediction of nerve exposure and nerve injury from the $\mathrm{CBCT}$ is due to the high precision and accuracy of CBCT compared to DPI.

Although the expected nerve exposure and injury from CBCT finding was $82.8 \%$ (Observer 1 and 2), only three cases $(8.57 \%)$ had nerve exposure and two cases (5.71\%) sustained nerve injury found clinically.

Previous studies have reported the superiority of CBCT to the DPT in providing clinicians on the topographic relationship between third molar and the IAC. It was reported that CBCT has higher sensitivity (93\%) and specificity $(77 \%)$ in predicting the exposure and injury to the IAN. ${ }^{21}$ Conversely, CBCT had a relatively low accuracy in predicting IAN exposure in those highly selected case when there is a close relationship between the IAC and thirds molar in this study. On the other hand, CBCT made it possible to identify the mandibular canal in both superior, inferior, and buccolingual dimension with greater accuracy compared to the DPT. Furthermore, it was proven to be more accurate in displaying the presence or absence of cortex separating the nerve and the root. ${ }^{22}$ However, CBCT machines are not available in general dental clinics as they are expensive to purchase.

A study done by Nakagawa in 2007, found $64.5 \%$ showed contact between third molar and IAC on the dental3D-CT. ${ }^{23}$ In the present study, the prevalence of close contact of the third molar root to IAC was $96.8 \%$ with the significant value being $p<0.05$. The relationship of impacted third molar to the IAC and cortical borders is important diagnostic information that can directly impact the outcome of surgery. Therefore, the practice of CBCT makes the surgical procedure become more efficient and less invasive. ${ }^{24}$

\section{Reliability of Determining Buccolingual Position of a Mandibular Third Molar from CBCT}

While CBCT has higher reliability in determining the buccolingual position of the IAC with respect to the third molar teeth and also has the ability to visualize the course of the mandibular canal, ${ }^{25}$ no high agreement between interobservers in determining the buccolingual position of the IAC has been found in this study. One of the explanations might be the different sagittal section or plane used by two observers to assess the buccolingual position of the IAC in relation to the mandibular third molar.

In this study, it was found that there was a moderate inter-observer agreement in the assessment of the lingual position of the IAC. The IAC was most often positioned at the lingual to the third molar than buccal. ${ }^{26} \mathrm{CBCT}$ image was able to confirm a remarkable change regarding the anatomical relationship between the IAC and third molar. Hence, it is significantly influenced the surgical approach to remove the tooth. ${ }^{27}$

\section{Reliability of these Findings to Surgery and Patients' Morbidity}

Only two patients sustained nerve disturbance after removal of the impacted mandibular third molar (lower right side). One of them sustained hyperesthesia at the lower right gingival area but not on the lip or chin while the other sustained paresthesia at the right side of lower lip and chin. The A and B-level dropout algorithm were performed for the first patient and 2nd patient sequentially. ${ }^{5}$ An earlier study by Ziccardi and Zuniga reported that the recovery of this type of injury is spontaneous within two to four months and up to one year for complete recovery without applying any level of the algorithm. ${ }^{28}$ However, in this study performing 3-level dropout algorithm, both patients recovered from paresthesia one month postoperatively.

It was noted that three patients who had nerve exposure intraoperatively sustained excessive hemorrhage from the socket, and none of them experienced any nerve disturbances postoperatively. The authors think that this bleeding is an indication of the close proximity of the IAN with the third molar teeth since it was mentioned in a report that the vasculature structures may be injured, but the nerve remains intact. ${ }^{9}$

Similar to other reports, it was observed that the period of the surgery did have an impact on the nerve injury. ${ }^{29}$ The surgery time of more than 30 minutes to an hour recorded an $8.57 \%$ of the cases of inferior alveolar nerve exposure. However, surgery time that took $\leq 30$ minutes caused postoperative nerve disturbance in $5.7 \%$ cases. So far, there is no scientific evidence suggesting that the duration of surgery had any relationship to nerve exposure and injury. However, the correlation between the operative times with postoperative pain has been reported unequivocally. ${ }^{30}$ It was suggested that the longer operating time, it reflected the difficulty of the surgery. Hence, the duration of tissue exposure is also increased, causing the higher incidence of the nerve injury. ${ }^{31}$

In this study, the incidence of paresthesia after third molar extraction cannot be correlated to the duration of 
surgery because of the existing close relationship of the tooth with the IAC (in the present selected sample) that may have contributed in the high rate of occurrence paraesthesia.

It must be mentioned here surgeons cannot, however, dismiss the usage of panoramic images in total. It is proven that DPI provides an optimum method of predicting neurological damage where the radiation exposure is low with cost also being low, thereby making this surgery more affordable. ${ }^{32}$ Further explanations on why there is a high prediction on nerve exposure and nerve injury but yet the results were not as expected, was because the surgery was done by experienced surgeons. They were aware of the high risk of nerve injury despite not having to view the CBCT. Therefore, surgeon's experience does play a great role in contributing to the avoidance of nerve injury following the impacted mandibular third molar extraction. This is supported by a study done by Sheperd et al. that the surgeon's experience contributes to the decrease in the postoperative complications. ${ }^{33}$

In all, there was no agreement between the two observers in identifying the relationship of the mandibular third molar with IAC using the four radiological markers, which makes the radiological sign from the DPI unreliable. However, it does have a diagnostic value in determining IAN exposure and injury. Cone-beam computed tomography provides more precise diagnostic information to determine the close relationship of the mandibular third molar to IAC compared to DPT.

\section{CONCLUSION}

All these promising results showed that DPI is still valuable for predicting the close relationship of the mandibular third molar to the IAC. Nevertheless, CBCT has the best accuracy in localizing the intimate contact between the mandibular third molar and the IAC.

\section{CLINICAL SIGNIFICANCE}

Although there was no significant finding from the CBCT for the incidence of IAN exposure and injury, CBCT was seen to be accurate in predicting the IAN exposure and injury. It was however very reliable in determining the buccolingual position of the root of mandibular third molar to the mandibular canal, unlike DPI. All these findings prove that CBCT contributes in the surgical plan, reduced operative time and patient morbidity.

\section{ACKNOWLEDGMENTS}

Special thanks to Dr Ha Kien Oon, Dr Ahmad Izzat Salleh, and Associate Professor Dr Norlide for their valuable advice and contribution in completing this research.

\section{REFERENCES}

1. Robert RC, Bacchetti P, Pogrel MA. Frequency of trigeminal nerve injuries following third molar removal. J Oral Maxillofac Surg 2005;63:732-735.

2. Ohman A, Kivijarvi K, Blomback U, Flygare L. Pre-operative radiographic evaluation of lower third molars with computed tomography. Dentomaxillofac Radiol 2006;35:30-35.

3. Rood JP, Shehab BA. The radiological prediction of inferior alveolar nerve injury during third molar surgery. Br J Oral Maxillofac Surg 1990;28:20-25.

4. Hill CM, Mostafa P, Thomas DW, Newcombe RG, Walker RV. Nerve morbidity following wisdom tooth removal under local and general anaesthesia. Br J Oral Maxillofac Surg 2001; 39:419-422.

5. Zuniga JR, Meyer RA, Gregg JM, Miloro M, Davis LF. The accuracy of clinical neurosensory testing for nerve injury diagnosis. J Oral Maxillofac Surg 1998;56:2-8.

6. Dessouky R, Xi Y. Role of MR Neurography for the Diagnosis of Peripheral Trigeminal Nerve Injuries in Patients with Prior Molar Tooth Extraction. AJNR Am J Neuroradiol 2018;39:162-169.

7. Friedland B, Donoff B, Dodson TB. The use of 3-dimensional reconstructions to evaluate the anatomic relationship of the mandibular canal and impacted mandibular third molars. J Oral Maxillofac Surg 2008;66:1678-1685.

8. Bell GW. Use of dental panoramic tomographs to predict the relation between mandibular third molar teeth and the inferior alveolar nerve. Radiological and surgical findings, and clinical outcome. Br J Oral Maxillofac Surg 2004;42:21-27.

9. Kipp DP, Goldstein BH, Weiss WWJR. Dysesthesia after mandibular third molar surgery: a retrospective study and analysis of 1,377 surgical procedures. J Am Dent Assoc 1980; 100:185-192.

10. Szalma J, Lempel E, Jeges S, Szabo G, Olasz L. The prognostic value of panoramic radiography of inferior alveolar nerve damage after mandibular third molar removal: retrospective study of 400 cases. Oral Surg Oral Med Oral Pathol Oral Radiol Endod 2010;109:294-302.

11. Blaeser BF, August MA, Donoff RB, Kaban LB, Dodson TB. Panoramic radiographic risk factors for inferior alveolar nerve injury after third molar extraction. J Oral Maxillofac Surg 2003;61:417-421.

12. Sedaghatfar M, August MA, Dodson TB. Panoramic radiographic findings as predictors of inferior alveolar nerve exposure following third molar extraction. J Oral Maxillofac Surg 2005;63:3-7.

13. Bundy MJ, CF Cavola, Dodson TB. Panoramic radiographic findings as predictors of mandibular nerve exposure following third molar extraction: digital versus conventional radiographic techniques. Oral Surg Oral Med Oral Pathol Oral Radiol Endod 2009;107:e36-40.

14. Tantanapornkul W, Okochi K, Bhakdinaronk A, Ohbayashi $\mathrm{N}$, Kurabayashi T. Correlation of darkening of impacted mandibular third molar root on digital panoramic images with cone beam computed tomography findings. DentoMaxillo-Facial Radiology 2009;38:11-16.

15. Pandey R, Ravindran C, Pandiyan D, Gupta A, Aggarwal A, Aryasri S. Assessment of Roods and Shehab criteria if one or more radiological signs are present in orthopantomogram and position of the mandibular canal in relation to the third molar apices using cone beam computed tomography: a radiographic study. Tanta Dental Journal 2018;15:33-38. 
16. Ali AS, Benton JA, Yates JM. Risk of inferior alveolar nerve injury with coronectomy vs surgical extraction of mandibular third molars-A comparison of two techniques and review of the literature. J Oral Rehabil 2018;45:250-257.

17. Monaco G, Montevecchi M, Bonetti GA, Gatto MR, Checchi L. Reliability of panoramic radiography in evaluating the topographic relationship between the mandibular canal and impacted third molars. J Am Dent Assoc 2004;135:312-318.

18. Ghaeminia H, Meijer GJ, Soehardi A, Borstlap WA, Mulder J, Berge SJ. Position of the impacted third molar in relation to the mandibular canal. Diagnostic accuracy of cone beam computed tomography compared with panoramic radiography. Int J Oral Maxillofac Surg 2009;38:964-971.

19. Wenzel A. It is not clear whether commonly used radiographic markers in panoramic images possess predictive ability for determining the relationship between the inferior alveolar nerve and the mandibular third molar. J Evid Based Dent Pract 2010;10:232-234.

20. Valmaseda-Castellon E, Berini-Aytes L, Gay-Escoda C. Inferior alveolar nerve damage after lower third molar surgical extraction: a prospective study of 1117 surgical extractions. Oral Surg Oral Med Oral Pathol Oral Radiol Endod 2001;92: 377-383.

21. Tantanapornkul W, Okouchi K, Fujiwara Y, Yamashiro M, Maruoka Y, Ohbayashi N et al. A comparative study of conebeam computed tomography and conventional panoramic radiography in assessing the topographic relationship between the mandibular canal and impacted third molars. Oral Surg Oral Med Oral Pathol Oral Radiol Endod 2007;103:253-259.

22. Feras Yabroudi SSP. Cone Beam Tomography (CBCT) as a Diagnostic Tool to Assess the Relationship between the Inferior Alveolar Nerve and Roots of Mandibular Wisdom Teeth. Smile Dental Journal 2012;7:12-17.

23. Nakagawa Y, Ishii H, Nomura Y, Watanabe NY, Hoshiba D, Kobayashi et al. Third molar position: reliability of panoramic radiography. J Oral Maxillofac Surg 2007;65:1303-1308.

24. Quereshy FA, Savell TA, Palomo JM. Applications of cone beam computed tomography in the practice of oral and maxillofacial surgery. J Oral Maxillofac Surg 2008;66: 791-796.

25. Ghaeminia H, Meijer GJ, Soehardi A, Borstlap WA, Mulder J, Berge SJ. Position of the impacted third molar in relation to the mandibular canal. Diagnostic accuracy of cone beam computed tomography compared with panoramic radiography. Int J Oral Maxillofac Surg 2009;38:964-971.

26. Maegawa H, Sano K, Kitagawa Y, Ogasawara T, Miyauchi $\mathrm{K}$, Sekine J et al. Preoperative assessment of the relationship between the mandibular third molar and the mandibular canal by axial computed tomography with coronal and sagittal reconstruction. Oral Surg Oral Med Oral Pathol Oral Radiol Endod 2003;96:639-646.

27. Ghaeminia H, Meijer GJ, Soehardi A, Borstlap WA, Mulder J, Vlijmen OJ et al. The use of cone beam CT for the removal of wisdom teeth changes the surgical approach compared with panoramic radiography: a pilot study. Int J Oral Maxillofac Surg 2011;40:834-839.

28. Ziccardi VB, Zuniga JR. Nerve injuries after third molar removal. Oral Maxillofac Surg Clin North Am 2007;19:105-115.

29. Sharma R, Srivastava A, Chandramala R. Nerve injuries related to mandibular third molar extractions. E-Journal of Dentistry 2012;2:146.

30. Bello SA, Adeyemo WL, Bamgbose BO, Obi EV, Adeyinka AA. Effect of age, impaction types and operative time on inflammatory tissue reactions following lower third molar surgery. Head Face Med 2011;7-8.

31. Benediktsdottir IS, Wenzel A, Petersen JK, Hintze H. Mandibular third molar removal: risk indicators for extended operation time, postoperative pain, and complications. Oral Surg Oral Med Oral Pathol Oral Radiol Endod 2004;97:438-446.

32. Smith AC, Barry SE, Chiong AY, Hadzakis D, Kha SL, Mok $\mathrm{SC}$ et al. Inferior alveolar nerve damage following removal of mandibular third molar teeth. A prospective study using panoramic radiography. Aust Dent J 1997;42:149-152.

33. Shepherd JP, Brickley M. Activity analysis: measurement of the effectiveness of surgical training and operative technique. Ann R Coll Surg Engl 1992;74:417. 